\title{
Influence of calcium on $\beta$-lactoglobulin denaturation kinetics: Implications in unfolding and aggregation mechanisms
}

\author{
J. Petit, ${ }^{1}$ A.-L. Herbig, A. Moreau, and G. Delaplace ${ }^{1}$ \\ INRA UR638 - Processus aux Interfaces et Hygiène des Matériaux, BP 20039, 59651 Villeneuve d'Ascq Cedex, France
}

\begin{abstract}
Much research dealing with the processing of milk by-products in heat exchangers has noted the key role of calcium in $\beta$-lactoglobulin ( $\beta-L G$ ) fouling behavior. Nevertheless, the manner by which Ca affects $\beta$-LG denaturation has rarely been quantified using reliable kinetic and thermodynamic data. To this end, the influence of $\mathrm{Ca}$ on $\beta$-LG denaturation mechanisms in simulated lactoserum concentrates was studied on the laboratory-scale under $100^{\circ} \mathrm{C}$ by HPLC analysis. The heat-treated solutions were composed of $53.3 \mathrm{~g} / \mathrm{L} \beta$-LG and were enriched in Ca at various concentrations $(0,66$, 132 , and $264 \mathrm{mg} / \mathrm{kg}$ ). The kinetic parameters (reaction order, activation energy, and frequency factor) associated with $\beta-\mathrm{LG}$ denaturation, along with the unfolding and aggregation thermodynamic parameters were deduced from these experiments and discussed with respect to $\mathrm{Ca}$ content. We found that the multistage process characterizing $\beta-\mathrm{LG}$ thermal denaturation is not greatly affected by $\mathrm{Ca}$ addition. In fact, the general model subdividing $\beta$-LG denaturation mechanisms in 2 steps, namely, unfolding and aggregation, remained valid for all tested $\mathrm{Ca}$ concentrations. The change in the predominant mechanism from unfolding to aggregation was observed at $80^{\circ} \mathrm{C}$ across the entire Ca concentration range. Moreover, the classical 1.5 reaction order value was unaffected by the presence of Ca. Interpretation of the acquired kinetic data showed that $\mathrm{Ca}$ addition led to a significant increase in kinetic rate, and more so in the aggregation temperature range. This indicates that Ca principally catalyzes $\beta-\mathrm{LG}$ aggregation, by lowering the Coulombian repulsion between the negatively charged $\beta$-LG reactive species, bridging $\beta$-LG proteins, or via an ion-specific conformational change. To a lesser extent, Ca favors $\beta$-LG unfolding, probably by disturbing the noncovalent binding network of native $\beta$-LG. Simultaneously, $\mathrm{Ca}$ has a slight protective role on the native and unfolded $\beta$-LG species, as shown by the increase in activation energy with $\mathrm{Ca}$ concentration.
\end{abstract}

\footnotetext{
Received April 21, 2011.

Accepted August 16, 2011.

${ }^{1}$ Corresponding author: jeremy.petit@centraliens.net and guillaume. delaplace@lille.inra.fr
}

The calculation of thermodynamic parameters related to $\beta$-LG denaturation confirmed this observation. A threshold effect in Ca influence was noted in this study: no further significant kinetic rate change was observed above $132 \mathrm{mg} / \mathrm{kg}$ of $\mathrm{Ca}$; at this concentration, the studied solution was an almost equimolar mixture of $\beta$-LG and Ca. Finally, we simulated the temporal evolution of $\beta$-LG species concentrations at diverse Ca contents at 3 holding temperatures. The simulations were based on the acquired kinetic parameters. This permitted us to highlight the greater effect of Ca on $\beta$-LG denaturation at high Ca content or for short-time heat treatments at temperatures near $100^{\circ} \mathrm{C}$, as in heat exchangers.

Key words: $\beta$-lactoglobulin, calcium, heat denaturation, thermodynamics

\section{INTRODUCTION}

Given that $\beta-\mathrm{LG}$ is the predominant whey protein in milk and dairy products, aggregation and fouling reactions under heat treatment are mainly governed by $\beta-L G$ denaturation kinetics. Whey proteins such as $\beta$-LG are today regarded as milk by-products with high functional properties, such as gelation, foaming, water retention, emulsification, and thermal stability (Mulvihill and Donovan, 1987). These functionalities are governed by the mean aggregate size of the globular proteins, following from the denaturation process, which depends on the physicochemical properties of the heated dairy product and the manner in which heat transfer was conducted. Heat transfer is highly dependent on the heat process equipment and operating conditions used, such as residence time and temperature profile inside the heat exchanger.

In addition, the thermal treatment of milk byproducts is complicated by the issue of fouling. Fouling is defined as the deposition of protein on the hot surfaces of heat exchangers and it causes decreases in heat exchange (René and Lalande, 1988; Benning et al., 2003) and increases in heat exchanger pressure drop (Grijspeerdt et al., 2004; Fryer et al., 2006) and in bacterial growth (Fryer et al., 2006; Jun and Puri, 2007). Fouling of industrial heat exchangers requires frequent cleanings, resulting in excessive use of water and harsh 
chemicals (René and Lalande, 1988; Georgiadis et al., 1998).

Kinetic rates are highly dependent on temperature but also extrinsic factors, such as $\beta-\mathrm{LG}$ and total protein concentrations in the dairy solution, $\mathrm{pH}$, ionic environment (e.g., Ca concentration), and so on. Unfortunately, data are lacking on $\beta$-LG denaturation kinetics in various physicochemical environments and thus, no predictive model is available to estimate a priori how a controlled chemical environment, such as the presence of $\mathrm{Ca}$ at a known concentration, will alter the $\beta$-LG denaturation kinetic parameters of raw dairy solutions.

The main findings concerning $\beta$-LG thermal behavior are summarized here, along with the effect of $\mathrm{Ca}$ on $\beta$-LG denaturation.

Bovine $\beta$-LG is one of the main whey proteins (along with $\alpha$-LA and BSA) and accounts for about $50 \%$ of the whey proteins (Mulvihill and Donovan, 1987; Havea et al., 2001), which corresponds to about $3.5 \mathrm{~g} / \mathrm{L}$ in milk (Lalande et al., 1989). Its molecular weight is about $18.3 \mathrm{~kg} / \mathrm{mol}$, its size approximately $3 \mathrm{~nm}$ (Mulvihill and Donovan, 1987), and it forms a native dimer at physiological $\mathrm{pH}$ and ambient temperature (Lalande et al., 1989; Sava et al., 2005). The isoelectric point of $\beta-\mathrm{LG}$ is around 5.3 (René and Lalande, 1988) and its denaturation temperature is estimated at about $77^{\circ} \mathrm{C}$ (Nielsen et al., 1995; Relkin, 1996; Havea et al., 2001; Linmark-Mansson et al., 2005), depending strongly on the chemical environment. The tertiary structure of $\beta$-LG is consolidated by 2 disulfide bonds. A thiol (-SH) group is hidden inside the hydrophobic core in the native state (Relkin, 1996; Labouré et al., 2004; Perez and Pilosof, 2004) and becomes exposed to solvent under heat treatment, allowing $\beta$-LG to form disulfide bonds with another whey protein via thiol group oxidation and disulfide interchange (Mulvihill and Donovan, 1987; Labouré et al., 2004). This latter phenomenon leads to the formation of $\beta$-LG aggregates.

The widely accepted model regarding $\beta$-LG heat denaturation (Mulvihill and Donovan, 1987; Tolkach and Kulozik, 2007) consists of a multistage process, as presented in Figure 1. At ambient temperature and physiological $\mathrm{pH}, \beta-\mathrm{LG}$ is found in solution as native dimers (René and Lalande, 1988; Kim and Lund, 1998), which dissociate into native monomers above $40^{\circ} \mathrm{C}$. Between 40 and $55^{\circ} \mathrm{C}, \beta-\mathrm{LG}$ undergoes a small change in its tertiary structure and forms the R-state, which has a very weak aptitude for aggregation (Mulvihill and Donovan, 1987; Tolkach and Kulozik, 2007). A temperature increase above 60 to $70^{\circ} \mathrm{C}$ causes reversible $\beta$-LG unfolding, which corresponds to an alteration of its tertiary structure by breakage of noncovalent bonds. This phenomenon, called the Tanford transition, leads to the formation of a "molten globule" state, able to induce $\beta$-LG aggregation by reaction of its exposed free thiol (Delplace et al., 1997; Santos et al., 2006b). The molten globule structure is temperature reversible, because covalent bonds are not broken, and $\beta$-LG refolds when the temperature returns to ambient. Incidentally, this last point indicates that a $\beta$-LG analysis at ambient temperature (such as that used in HPLC) can only provide the total soluble concentration; that is, the sum of native and molten globule $\beta$-LG (Mulvihill and Donovan, 1987; Tolkach and Kulozik, 2007). The formation of the molten globule state ends at 80 to $90^{\circ} \mathrm{C}$. Finally, above 130 to $140^{\circ} \mathrm{C}$, irreversibly denatured $\beta-\mathrm{LG}$ are formed as a result of the destruction of the protein secondary structure, and this latter $\beta$-LG form is also prone to aggregation. Aggregates can then react with R-state, molten globule, and irreversibly denatured $\beta$-LG to form larger aggregates (Tolkach and Kulozik, 2007).

To give a concise view of the $\beta$-LG heat-induced denaturation at temperatures between 60 and $100^{\circ} \mathrm{C}$, Oldfield et al. (2005) proposed a 2-step reaction to model the denaturation mechanism: $N \rightarrow U \rightarrow A$ [1]. Under heat treatment, native $\beta$-LG $(\boldsymbol{N})$ unfolds to form molten globule $\beta$-LG or reversibly unfolded $\beta$-LG $(\boldsymbol{U})$. Then, these unfolded species can react with native or other unfolded $\beta$-LG via disulfide interchange or thiol oxidation to form denatured $\beta-\mathrm{LG}(\boldsymbol{A})$; that is, aggregates. Each step of the denaturation reaction (unfolding and aggregation) is considered kinetically driven.

In spite of this simplification of the mechanism, Tolkach and Kulozik (2007) have shown that this novel

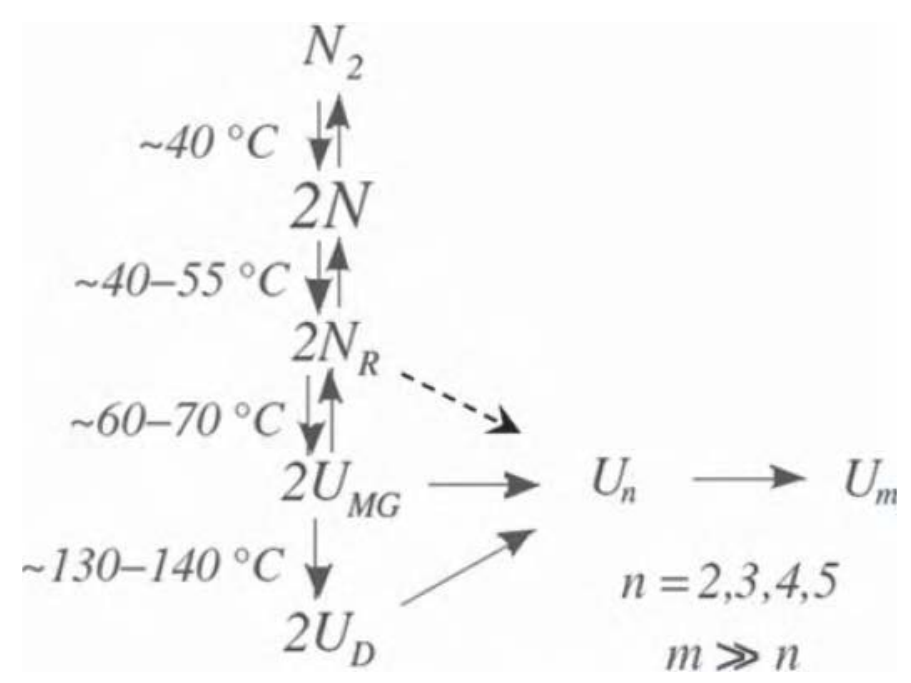

Figure 1. Multistage process characterizing $\beta$-LG thermal denaturation (extracted and adapted from Tolkach and Kulozik, 2007). N $=$ native $\beta$-LG; $\mathrm{N}_{\mathrm{R}}=\mathrm{R}$-state $\beta$-LG; $\mathrm{U}_{\mathrm{MG}}=$ molten globule $\beta$-LG; $\mathrm{U}_{\mathrm{D}}$ $=$ irreversibly denatured $\beta-\mathrm{LG} ; \mathrm{U}_{\mathrm{n}}$ and $\mathrm{U}_{\mathrm{m}}=$ aggregates, respectively composed of $n$ and $m \beta$-LG units. 
reaction kinetic approach, associated with HPLC quantification of soluble proteins, allows the evaluation of native, unfolded, and denatured $\beta$-LG concentrations as a function of heating time. Consequently, it can also be used for the kinetic characterization of $\beta$-LG unfolding and aggregation reactions. The denaturation reaction mentioned in numerous papers (Dannenberg and Kessler, 1986; De Wit, 1990; Gotham et al., 1992; Roefs and De Kruif, 1994; Anema and McKenna, 1996; Donato et al., 2009; Galani and Apenten, 1999; Oldfield et al., 2005; Tolkach and Kulozik, 2007) corresponds to the pathway from the native to the aggregated state $(N \rightarrow A)$ with the reaction mechanism adopted in this paper (see equation [1]).

The $\beta$-LG denaturation reaction is influenced by many parameters, such as solution chemistry, thermal history during heat treatment (Foster et al., 1989; Schraml and Kessler, 1996; Santos et al., 2006b), hydrodynamics (Delplace et al., 1997; Zumaeta et al., 2007), and heat exchanger surface type (Kim and Lund, 1998; Rosamininho et al., 2007).

The role of ionic $\mathrm{Ca}$ is important in $\beta$-LG denaturation and aggregation. According to the literature, $\mathrm{Ca}$ is involved in 2 aspects of $\beta-\mathrm{LG}$ denaturation and aggregation mechanisms. On one hand, $\mathrm{Ca}$ is involved in growth and deposition of $\beta$-LG aggregates (Mulvihill and Donovan, 1987); it is expected to form covalent bridges between $\beta$-LG monomers, aggregates, and surface minerals (Anema and McKenna, 1996; Changani et al., 1997), which strengthens the aggregate or deposit structure (Britten et al., 1988). Consequently, aggregates formed in a Ca-enriched solution will be denser and their size will generally increase (Mulvihill and Donovan, 1987; Xiong, 1992); however, under particular environmental conditions, it has been reported that Ca decreases the aggregate size (Simmons et al., 2007). Calcium also participates in the denaturation mechanism by lowering the temperature at which $\beta$-LG begins to denature (De Wit, 1990; Simmons et al., 2007). On the other hand, an increase in Ca concentration helps to raise the ionic strength. The presence of numerous ions in a $\beta$-LG solution favors aggregates growth (Verheul et al., 1998; Allen and Smith, 2001; Schmitt et al., 2007) and surface fouling (De Wit, 1990; Relkin, 1996; Simmons et al., 2007) by neutralizing the protein surface charge and thus reducing drastically Coulombian repulsion.

The interaction between $\mathrm{Ca}$ and $\beta-\mathrm{LG}$ has been extensively investigated recently and it was established that $\mathrm{Ca}$ is able to influence $\beta$-LG denaturation and aggregation mechanisms in 3 different ways (Jeyarajah and Allen, 1994; Simons et al., 2002; O'Kennedy and Mounsey, 2009), depending on the environmental conditions. First, Ca can cause the intermolecular cross- linking of adjacent negatively charged groups (such as carboxylic groups) of $\beta-\mathrm{LG}$, leading to $\beta-\mathrm{LG}$ aggregation by bridging. Second, ionic Ca takes part in the intramolecular electrostatic shielding of $\beta$-LG negative charges, which tends to lower Coulombian repulsion between $\beta$-LG proteins and favors $\beta$-LG aggregation by hydrophobic bonds. Third, Ca can induce specific conformational changes in the $\beta$-LG tertiary structure, leading to local unfolding of $\beta$-LG and exposition of its free thiol group.

By studying Ca-binding features of $\beta$-LG at ambient temperature or after heat treatment at various temperatures, some authors have found that the role of Ca concerns principally the shielding of $\beta-L G$ charge (O'Kennedy and Mounsey, 2009) and the ion-specific interaction (Jeyarajah and Allen, 1994; Simons et al., 2002). Indeed, irreversibly denatured $\beta$-LG have a greater affinity for $\mathrm{Ca}$ than native or molten globule $\beta$-LG (Jeyarajah and Allen, 1994), which is explained by the higher exposition of carboxylic groups in the denatured $\beta$-LG species (Simons et al., 2002). In consequence, Ca would be expected to affect essentially $\beta$-LG aggregation. Furthermore, the concentration of Ca required to trigger $\beta$-LG aggregation increases when more $\mathrm{Ca}$ ions are bound to $\beta-\mathrm{LG}$, which makes the intermolecular $\beta$-LG- $\mathrm{Ca}^{2+}-\beta$-LG cross-linking hypothesis unlikely (Simons et al., 2002).

Because divalent anions such as $\mathrm{Ca}^{2+}$ have a specific action on $\beta$-LG denaturation and aggregation mechanisms that cannot be reproduced with monovalent cations, it was deduced that Ca acts on $\beta$-LG not only by shielding its electric charges but also via an ion-specific interaction (Jeyarajah and Allen, 1994). In fact, Ca induces a local unfolding of $\beta-\mathrm{LG}$, which exposes the previously hidden free thiol group and allows the formation of intermolecular disulfide bonds. This effect is concomitant with an increase in $\beta$-LG hydrophobicity, which further increases the propensity of $\beta-\mathrm{LG}$ to aggregate (Jeyarajah and Allen, 1994).

Many dairy fouling studies were performed with milk by-products containing different $\mathrm{Ca}$ concentrations, protein types and concentrations, and ionic environments. Consequently, some trends can be deduced about the role played by $\mathrm{Ca}$ in $\beta$-LG unfolding, aggregation, and deposition reactions. However, specific studies conducted on the laboratory scale and dedicated to quantifying the effect of $\mathrm{Ca}$ on the chemical behavior of $\beta$-LG have not been carried out. To quantify the role of $\mathrm{Ca}$ in $\beta$-LG denaturation and fouling processes, the evolution of the kinetic parameters with Ca concentration has to be determined.

In this study, kinetic and thermodynamic parameters related to heat-induced $\beta$-LG denaturation under $100^{\circ} \mathrm{C}$ were determined by HPLC for a $53.3 \mathrm{~g} / \mathrm{L} \beta-\mathrm{LG}$ solution 
containing various concentrations of calcium chloride at neutral $\mathrm{pH}$. The evolution of these kinetic parameters with temperature and $\mathrm{Ca}$ concentration was discussed and the associated thermodynamic data were calculated. These experiments enabled us to determine the influence of $\mathrm{Ca}$ on $\beta$-LG unfolding and aggregation at temperatures below $100^{\circ} \mathrm{C}$. Denaturation $\beta-\mathrm{LG}$ at various Ca concentrations and temperatures was simulated to illustrate the effect of $\mathrm{Ca}$ on $\beta$-LG denaturation as a function of temperature.

\section{MATERIALS AND METHODS}

\section{Chemical and Reagents}

For the whole experiment, the $53.3 \mathrm{~g} / \mathrm{L} \beta-\mathrm{LG}$ solutions with various $\mathrm{Ca}$ concentrations were prepared by mixing $6 \mathrm{~g}$ of $\beta$-LG powder (industrial powder: $\beta$-LG $88.85 \%$, $\alpha$-lactalbumin $<0.01 \%$, Ca $0.03 \%$, phosphate $0.07 \%$, sodium $0.76 \%$, lactose $0.4 \%$ ) in $94 \mathrm{~g}$ of deionized water (Millipore, Bedford, MA) at $40^{\circ} \mathrm{C}$. Then, different quantities (ranging from 0 to $660 \mu \mathrm{L}$ ) of a molar Ca chloride $\left(\mathrm{CaCl}_{2} 96 \%\right.$, Prolabo, VWR International, West Chester, PA) solution were added to the $\beta$-LG solution to obtain stock solutions containing $5.33 \%$ (wt/ wt) $\beta$-LG and $0,66,132$, or $264 \mathrm{mg} / \mathrm{kg}$ Ca (i.e., 0, 1.65 , 3.3 , and $6.6 \mathrm{mmol} / \mathrm{L}$ ). These solutions were maintained at $40^{\circ} \mathrm{C}$ for $2 \mathrm{~h}$ for complete dissolution of the $\beta$-LG powder. The $\mathrm{pH}$ of these solutions was close to 6.8 .

The heat-treated samples were prepared for HPLC analysis according to the following protocol: after dilution with deionized water when necessary, small quantities of molar acetic acid (Normapur, Prolabo) were added until the $\mathrm{pH}$ reached 4.6 to precipitate aggregates. After $1 \mathrm{~h}$ at rest, the samples were centrifuged (6K15, Sigma, St. Louis, MO) at $9,056 \times g$ and $4^{\circ} \mathrm{C}$ for $30 \mathrm{~min}$. The native $\beta$-LG containing supernatant was finally collected for HPLC analysis.

The mobile phases used in HPLC were $0.1 \%$ (vol/ vol) trifluoroacetic acid (99\%, Acros Organics, Thermo Fisher Scientific, Waltham, MA) in deionized water, and $0.1 \%$ trifluoroacetic acid in a mixture of $80 \%$ acetonitrile (HPLC grade, Thermo Fisher Scientific) and $20 \%$ deionized water. Calibration standards in the range from 1 to $5 \mathrm{~g} / \mathrm{L}$ were prepared by dissolving the $\beta$-LG powder in deionized water.

\section{Heat Treatment}

All thermal denaturation experiments were conducted on twelve 1.4-mL samples for each Ca concentration. Before submitting samples to the desired holding temperature, the samples were preheated to $60^{\circ} \mathrm{C}$ (below the $\beta$-LG denaturation temperature of $77^{\circ} \mathrm{C}$; Nielsen et al., 1995; Linmark-Mansson et al., 2005). This was achieved by putting samples of stock solution in polypropylene tubes (Eppendorf, Hamburg, Germany) in the first water bath at $62^{\circ} \mathrm{C}$ for $30 \mathrm{~min}$.

The temperature increase from the preheating temperature $\left(60^{\circ} \mathrm{C}\right)$ to the desired holding temperature was performed by placing the samples in a second water bath whose temperature was maintained $10^{\circ} \mathrm{C}$ higher than the holding temperature to shorten the heat increase time. The first sample was acquired when the sample temperature was equal to the holding value. The sample temperature was monitored by following the temperature evolution of a reference vial filled with the stock solution, in which a temperature probe was inserted.

The holding temperature, ranging from 68 to $96^{\circ} \mathrm{C}$, was maintained for a period sufficient for significant denaturation by means of a third water bath whose temperature was fixed at $2^{\circ} \mathrm{C}$ higher than the desired temperature (e.g., $98^{\circ} \mathrm{C}$ for a holding temperature of $96^{\circ} \mathrm{C}$ ). Immersion of a sample in this last water bath corresponded to time zero. At different times, the samples were removed from the last water bath and cooled immediately in a beaker half filled with melting ice.

\section{HPLC}

The native $\beta$-LG concentration in the samples after $\mathrm{pH}$ adjustment and centrifugation was evaluated with HPLC. The chromatographic system (Waters, Milford, MA) included a 717 Plus autosampler, a 616 quadratic pump system, a Jones Model 7971 column oven, a CLHP ACE $300 \AA$ C4 separation column $(25 \mathrm{~cm} \times$ $4.6 \mathrm{~mm}$ ), and the associated guard column (Advanced Chromatography Technologies, Aberdeen, UK), a 486 UV-visible spectrophotometer, and acquisition software (Millenium 3.2, Waters).

The HPLC analyses were carried out in the following conditions: flow rate $1 \mathrm{~mL} / \mathrm{min}$, injection volume of $10 \mu \mathrm{L}$, temperature of $30^{\circ} \mathrm{C}$, detection wavelength of $214 \mathrm{~nm}$, and gradient elution. Analyses were repeated 3 times for each standard or sample. The calibration was carried out in the range 1 to $5 \mathrm{~g} / \mathrm{L}$, which involved diluting the samples before $\mathrm{pH}$ adjustments. A daily column conditioning was achieved by eluting acetonitrile at $1 \mathrm{~mL} / \mathrm{min}$ for $1 \mathrm{~h}$ to restore the column properties.

The sample concentrations were calculated by averaging the 3 measured chromatographic areas and converting this area value into a $\beta$-LG concentration by means of the HPLC calibration curve.

\section{Determination of Kinetic Parameters}

The reaction model used in this study is derived from the work of Oldfield et al. (2005) and Anema and McK- 
enna (1996). It is based on the approach considering the unfolding and aggregation mechanisms as kinetically driven (see Eq. [1]).

Determination of the Denaturation Rate Constant. First, an analytical technique such as HPLC is solely able to evaluate the $\beta$-LG total soluble concentration $C_{s}$; however, native and unfolded $\beta$-LG concentrations $\left(C_{N}\right.$ and $\left.C_{U}\right)$ remain inaccessible with this analytical technique. Nevertheless, the denaturation reaction concerns the transformation of soluble species (native and unfolded $\beta$-LG) into insoluble species (aggregates), which is described by the chemical equation $N \rightarrow A$ and defined in equation 2 :

$$
-\frac{\mathrm{d} C_{s}}{\mathrm{~d} t}=k_{n} C_{s}^{n}
$$

where $C_{s}=$ soluble $\beta-\mathrm{LG}$ concentration $(\mathrm{mol} / \mathrm{L})$ equal to $C_{N}+C_{U}, k_{n}=$ denaturation rate constant for a reaction order equal to $n\left(\mathrm{~g}^{1-n} \cdot \mathrm{L}^{n-1} \cdot \mathrm{s}^{-1}\right)$, and $n=$ denaturation reaction order.

The denaturation equation resolution provides different $C_{s}$ expressions depending on the reaction order value: For $n \neq 1, C_{s}(t)=C_{s}{ }^{\circ}\left[1+(n-1) \cdot k_{n} \cdot\left(C_{s}^{\circ}\right)^{n-1} t\right]^{1 / 1-n}$, [3], and for $n=1, C_{s}(t)=C_{s}{ }^{\circ} e^{-k_{1} t}[4]$, where $C_{s}^{\circ}=$ initial (time zero) $\beta-\mathrm{LG}$ total soluble concentration $(\mathrm{g} / \mathrm{L})$ and $t=$ time (s).

Rewriting the previous equations allows the calculation of the denaturation rate constant at a given temperature.

For $n \neq 1$,

$$
\frac{\left(\frac{C_{s}(t)}{C_{s}{ }^{\circ}}\right)^{1-n}-1}{(n-1)\left(C_{s}^{\circ}\right)^{n-1}}=k_{n} t .
$$

And for $n=1$,

$$
-\ln \left(C_{s}(t) / C_{s}^{\circ}\right)=k_{1} t
$$

So, for $n$ varying from 1 to 2 by 0.1 steps,

$$
-\ln \left(C_{s}(t) / C_{s}^{\circ}\right)
$$

for $n=1$, or

$$
\frac{\left(\frac{C_{s}(t)}{C_{s}^{\circ}}\right)^{1-n}-1}{(n-1)\left(C_{s}^{\circ}\right)^{n-1}}
$$

Journal of Dairy Science Vol. 94 No. 12, 2011 otherwise were plotted as a function of time, and linear regressions of experimental data were performed. The adequate reaction order corresponded to the linear regression that best fits the experimental data plotted in this way. For each temperature, the corresponding denaturation rate constant was deduced from the linear regression slope.

Temperature Dependence of the Denaturation Rate Constant: Use of the Arrhenius Plot. The relation between the denaturation kinetic rate and the heat treatment temperature is given by the Arrhenius equation:

$$
\ln \left(k_{n}\right)=\ln \left(k_{n}^{\circ}\right)-\frac{E_{A_{n}}}{R T},
$$

where $k_{n}{ }^{\circ}=$ denaturation frequency factor $\left(\mathrm{g}^{1-n} \cdot \mathrm{L}^{n-1} \cdot \mathrm{s}^{-1}\right)$, $E_{A_{n}}=$ denaturation activation energy $(\mathrm{J} / \mathrm{mol}), R=$ universal gas constant $\left(\approx 8.314 \mathrm{~J} \cdot \mathrm{K}^{-1} \cdot \mathrm{mol}^{-1}\right)$, and $T=$ temperature $(\mathrm{K})$.

An example of Arrhenius plot obtained with $264 \mathrm{mg} /$ $\mathrm{kg} \mathrm{Ca}$ is represented in Figure 2. The Arrhenius plot of Figure 2 draws the evolution of the denaturation rate constant logarithm with inverse temperature. As expected from equation [7], the denaturation rate constant logarithm varied linearly with $1 / T$, with a slope equal to $-E_{A} / R$, but in the case of $\beta-\mathrm{LG}$ denaturation, 2 mechanisms appear on this graph, separated by an Arrhenius critical temperature $\left(T_{c}\right)$ of about $80^{\circ} \mathrm{C}$. This slope break delimits 2 temperature ranges: below the critical temperature, the denaturation reaction is limited by the unfolding reaction (the unfolding reaction is slower than aggregation) and unfolded $\beta-L G$ represents a fraction of total soluble $\beta-\mathrm{LG}$, which increases faster with temperature. For temperatures above the critical temperature, $\beta$-LG denaturation is limited by the aggregation reaction and in that case, aggregation is the slower reaction.

Consequently, linear regressions of the experimental values in the 2 temperature ranges permit us to determine the kinetic parameters (frequency factors and activation energies) related to the unfolding (Eq. [8]) and aggregation (Eq. [9]) phenomena:

$$
\ln \left(k_{u n f}\right)=\ln \left(k_{u n f}^{\circ}\right)-\frac{E_{A, u n f}}{R T},
$$

where $k_{u n f}=$ unfolding constant rate, depending on $n$ $\left(\mathrm{g}^{1-n} \cdot \mathrm{L}^{n-1} \cdot \mathrm{s}^{-1}\right), \quad k_{\text {unf }}^{\circ}=$ unfolding frequency factor $\left(\mathrm{g}^{1-n} \cdot \mathrm{L}^{n-1} \cdot \mathrm{s}^{-1}\right)$, and $E_{A, \text { unf }}=$ unfolding activation energy $(\mathrm{J} / \mathrm{mol})$; and

$$
\ln \left(k_{\text {agg }}\right)=\ln \left(k_{\text {agg }}^{\circ}\right)-\frac{E_{A, a g g}}{R T},
$$




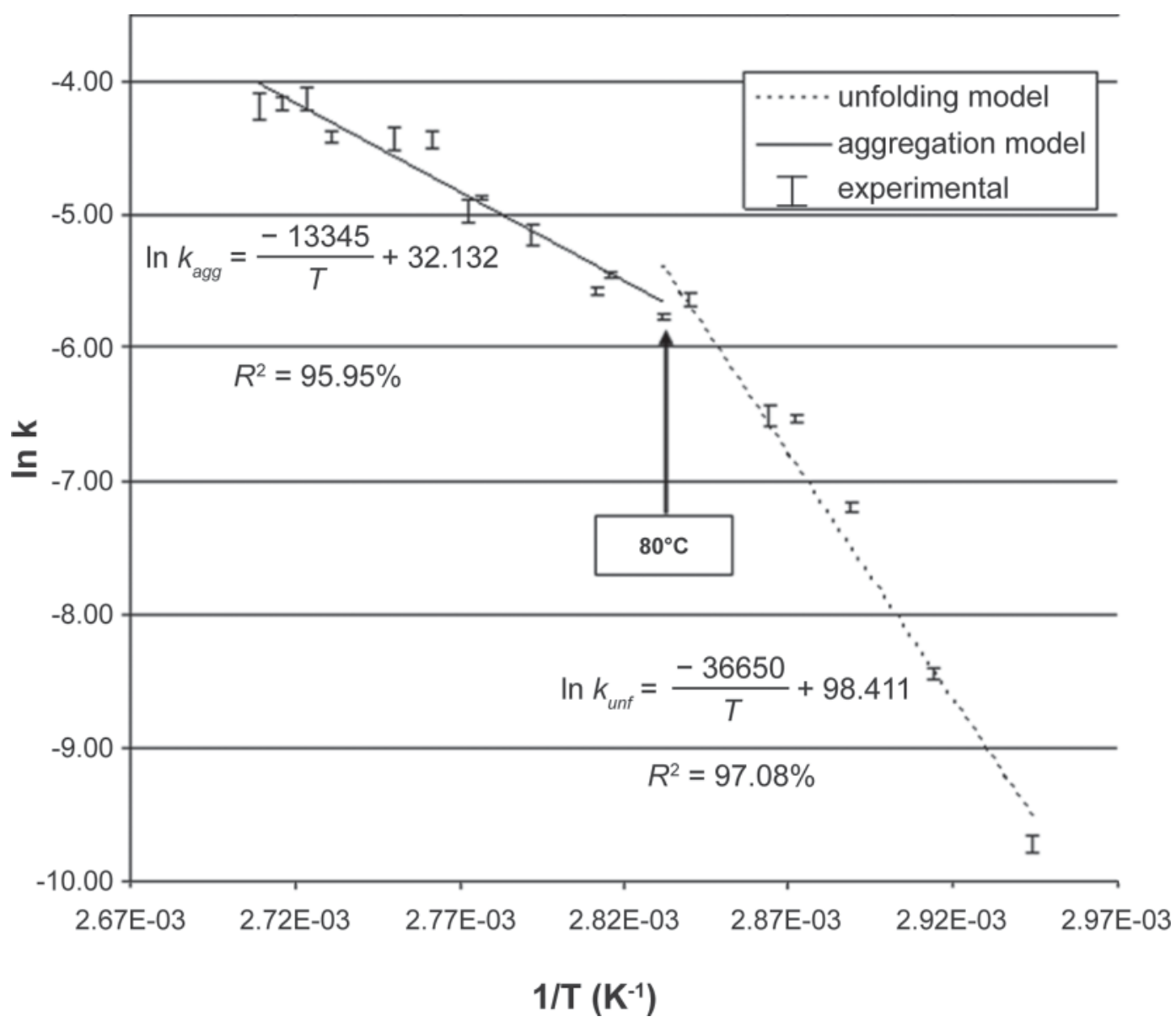

Figure 2. Arrhenius plot obtained for the $53.3 \mathrm{~g} / \mathrm{L} \beta$-LG and $264 \mathrm{mg} / \mathrm{kg}$ Ca solutions. $\mathrm{T}=$ temperature in Kelvin $(\mathrm{K}) ; \mathrm{k}_{\mathrm{n}}=\mathrm{denaturation}$ reaction rate $\left(\mathrm{g}^{1-\mathrm{n}} \cdot \mathrm{L}^{\mathrm{n}-1} \cdot \mathrm{s}^{-1}\right)$.

where $k_{a g q}=$ aggregation constant rate, depending on $n$ $\left(\mathrm{g}^{1-n} \cdot \mathrm{L}^{n-1} \cdot \mathrm{s}^{-1}\right), k_{\text {agq }}^{\circ}=$ aggregation frequency factor $\left(\mathrm{g}^{1-n} \cdot \mathrm{L}^{n-1} \cdot \mathrm{s}^{-1}\right)$, and $E_{A, a g g}=$ aggregation activation en$\operatorname{ergy}(\mathrm{J} / \mathrm{mol})$.

These kinetic parameters fully define $\beta$-LG denaturation in each temperature range and could be used to simulate the evolution of concentrations of the different $\beta$-LG species in a given temperature profile, as illustrated later in this paper.

\section{Calculation of Thermodynamic Denaturation Parameters}

Thermodynamic denaturation parameters can be calculated for the unfolding and aggregation reactions, which provides information about the structural changes occurring in the 2 temperature ranges in the Arrhenius plot. The equations used to evaluate the free energy $\Delta \mathrm{G}$, enthalpy $\Delta \mathrm{H}$, and entropy $\Delta \mathrm{S}$ of activation of the $\beta-\mathrm{LG}$ denaturation reaction are listed by Anema and McKenna (1996) and reported here:

$$
\begin{gathered}
k=\frac{k_{B} T}{h} \exp \left(-\frac{\Delta \mathrm{G}}{R T}\right), \\
\Delta \mathrm{H}=E_{A}-R T, \\
\Delta \mathrm{G}=\Delta \mathrm{H}-T \Delta \mathrm{S}, \\
k=k_{n} \cdot C_{s}{ }^{o n-1},
\end{gathered}
$$

where $k=$ denaturation kinetic rate that is independent of the reaction order $\left(\mathrm{s}^{-1}\right), k_{B}=$ Boltzmann constant $\left(\approx 1.38 \times 10^{-23} \mathrm{~J} / \mathrm{K}\right)$, and $h=$ Planck constant $(\approx 6.62$ $\left.\times 10^{-34} \mathrm{~J} \cdot \mathrm{s}\right)$. 
In this context, the thermodynamic constants are specific to each Arrhenius temperature range and should be determined separately for unfolding and aggregation reactions by using the same formalism as in equations [10] to [13].

\section{Computation of the Evolution of Denaturation Level with Time and Ca Concentration at Different Temperatures}

The temporal evolution of the $\beta$-LG denaturation level (i.e., the aggregate fraction) for the 4 studied $\mathrm{Ca}$ concentrations and 3 holding temperatures (70, 80, and $90^{\circ} \mathrm{C}$ ) were simulated by using the Scilab software (Digiteo, Saclay, France). These simulations were based on the classical denaturation mechanism and its associated kinetic parameters obtained with the HPLC method, along with the temporal discretization of the simulated temperature profiles. We fixed the time step at $1 \mathrm{~s}$, which provided sufficient accuracy. The total heating time was equal to $60 \mathrm{~min}$ in our simulation.

The simulated heat treatment profiles were similar to those recorded when performing the denaturation experiments. These temperature profiles were approximately linear in 2 successive time ranges: after a rapid and linear temperature increase from $60^{\circ} \mathrm{C}$ to the holding temperature (the second water bath), the temperature remained almost constant at the holding value (in the third water bath). The approximate times needed to heat the $\beta$-LG samples from $60^{\circ} \mathrm{C}$ to the holding temperatures in the second water bath were 15 s at $70^{\circ} \mathrm{C}, 45 \mathrm{~s}$ at $80^{\circ} \mathrm{C}$, and $60 \mathrm{~s}$ at $90^{\circ} \mathrm{C}$. With heating times less than $1 \mathrm{~min}, \beta$-LG began to denature significantly from 70 to $75^{\circ} \mathrm{C}$. This justified our choice to set the initial temperature at $60^{\circ} \mathrm{C}$ in all experiments, and to simulate the denaturation level evolution only from $60^{\circ} \mathrm{C}$. The mean heating rate ranged from 0.33 to $0.67^{\circ} \mathrm{C} / \mathrm{s}$ in these experiments.

\section{RESULTS AND DISCUSSION}

\section{Influence of $\mathrm{Ca}$ on the $\beta-L G$ Denaturation Reaction Order}

The $\beta$-LG denaturation reaction order found in the literature was generally 1.5, although in some conditions it should be taken equal to 2 (Mulvihill and Donovan, 1987; Relkin, 1996). To settle this issue with respect to the various $\mathrm{Ca}$ concentrations, we performed the same heat treatment to the $53.3 \mathrm{~g} / \mathrm{L} \beta$-LG solutions containing different $\mathrm{Ca}$ amounts. Figure 3 shows the experimental data acquired with the previously described method applied to study the effect of Ca up to $264 \mathrm{mg} /$ $\mathrm{kg}$ on $\beta$-LG denaturation at about $75^{\circ} \mathrm{C}$; that is, in the unfolding limited range. Furthermore, this figure shows the models obtained with the 1.5 and 2 reaction orders at Ca concentrations of $0,66,132$, or $264 \mathrm{mg} / \mathrm{kg}$.

As seen in Figure 3, the 1.5 reaction order model was the best able to describe $\beta$-LG denaturation at $75^{\circ} \mathrm{C}$. Indeed, the 1.5 reaction order model precisely fitted the experimental data at all $\mathrm{Ca}$ concentrations. Regarding the 2 reaction order model, the theoretical curves diverged noticeably from the experimental points, which confirms the 1.5 denaturation reaction order hypothesis. The Ca concentration did not seem to affect the denaturation reaction order in the unfolding limited range. Thus, no significant change in the unfolding mechanism reaction order can be attributed to the presence of $\mathrm{Ca}$.

This finding may differ in the upper temperature range, where aggregation is the limiting reaction, as $\mathrm{Ca}$ is expected to be highly involved in the aggregation mechanism (Mulvihill and Donovan, 1987) and structure (Britten et al., 1988) by increasing the size of aggregates (Verheul et al., 1998; Allen and Smith, 2001; Schmitt et al., 2007) and lowering the $\beta$-LG denaturation temperature, which favors aggregate formation (De Wit, 1990; Simmons et al., 2007). Figure 4 displays the acquired results at an approximate temperature of $90^{\circ} \mathrm{C}$ for the different experimental solutions. Once again, the 1.5 reaction order led to the more accurate modeling of the experimental data. Indeed, the results at $\mathrm{Ca}$ concentrations of 0 and $66 \mathrm{mg} / \mathrm{kg}$ were properly fitted by the 1.5 reaction order model, as were the first points at $132 \mathrm{mg} / \mathrm{kg}$ of Ca. However, the few points that seemed aberrant at this latter concentration could not be fitted by the same trend, indicating the lack of precision concerning the determination of $\beta-\mathrm{LG}$ concentration. It is interesting to note that the 2 reaction order model permitted a better fit of the $264 \mathrm{mg} /$ $\mathrm{kg}$ concentration results, even though the 1.5 reaction order was also suitable. However, the 1.5 reaction order correctly modeled the whole experimental set. The influence of $\mathrm{Ca}$ in the aggregation-limited temperature range appeared to be more important at higher $\mathrm{Ca}$ concentrations, because the aggregation mechanism was better described with a 2 reaction order. This latter finding confirms results found by some researchers (Dannenberg and Kessler, 1986; Verheul et al., 1998; Santos et al., 2006a; Tolkach and Kulozik, 2007; De Wit, 2009), particularly that of De Jong et al. (1992). Nevertheless, the observation made in this study may be the consequence of the lack of precision at the lower $\beta$-LG concentrations, as the samples over $1.5 \mathrm{~min}$ at a Ca concentration of $264 \mathrm{mg} / \mathrm{kg}$ had a concentration below the HPLC standard lowest concentration of $1 \mathrm{~g} / \mathrm{L}$. 


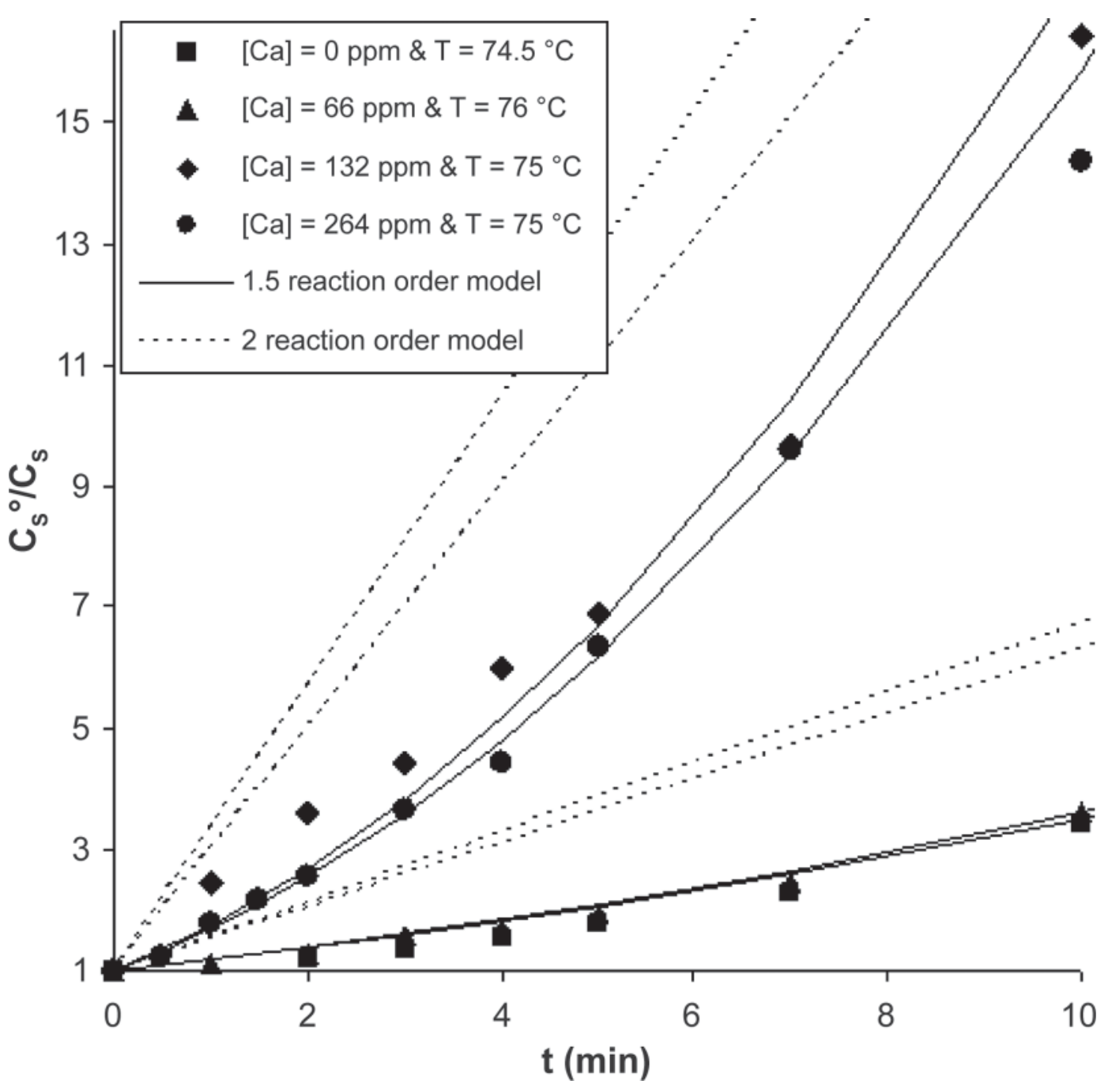

Figure 3. Comparison between the denaturation models based on different reaction orders (1.5 or 2$)$ at approximately $75^{\circ} \mathrm{C}$ and various $\mathrm{Ca}$ concentrations. $\mathrm{t}=$ time $(\mathrm{min}) ; \mathrm{C}_{\mathrm{S}}=\beta$-LG native concentration at time $\mathrm{t}(\mathrm{g} / \mathrm{L}) ; \mathrm{C}_{\mathrm{S}}{ }^{\circ}=$ initial $\beta$-LG native concentration $(53.3 \mathrm{~g} / \mathrm{L})$.

The imprecision of $\beta$-LG sample concentrations over $3 \mathrm{~min}$ at a Ca concentration of $132 \mathrm{mg} / \mathrm{kg}$ illustrated this fact.

Moreover, by comparing Figures 3 and 4 it can be seen that denaturation rates follow an increasing trend with temperature: for instance, a $C_{s}{ }^{\circ} / C_{s}$ of 3 was achieved in approximately $10 \mathrm{~min}$ at $75^{\circ} \mathrm{C}$ and $\mathrm{Ca}$ concentration of 0 or $66 \mathrm{mg} / \mathrm{kg}$, whereas it took only 1 to 2 min at $90^{\circ} \mathrm{C}$.

\section{Temperature Dependence of the Unfolding and Aggregation Kinetic Rates}

The Arrhenius plot for the denaturation reaction at various Ca concentrations has been drawn in Figure 5. This figure depicts the temperature influence on the $\beta$-LG denaturation kinetic rate in the temperature range from 68 to $96^{\circ} \mathrm{C}$. Each symbol refers to one experiment at fixed temperature and $\mathrm{Ca}$ concentration. On Figure 5 , the associated uncertainties (i.e., the kinetic rate logarithm prediction intervals) were also represented. They were calculated by using the integral of Student's probability density function at $95 \%$ confidence level and spreading the errors.

As expected, a sharp bend can be observed in the Arrhenius plot around $80^{\circ} \mathrm{C}$ (more precisely, between 79 and $82^{\circ} \mathrm{C}$ depending on the Ca concentration). This critical temperature splits the Arrhenius plot in 2 temperature ranges: below $80^{\circ} \mathrm{C}$, the $\beta-\mathrm{LG}$ denaturation reaction is unfolding limited, which means that aggregation is faster than unfolding, and over $80^{\circ} \mathrm{C}$, all $\beta$-LG molecules are quickly converted to unfolded species and aggregation is thus the limiting reaction. The literature indicates that the Arrhenius critical temperature is found between 85 and $95^{\circ} \mathrm{C}$ (Dannenberg and Kessler, 1986; Lalande et al., 1989; Anema and McKenna, 1996; 


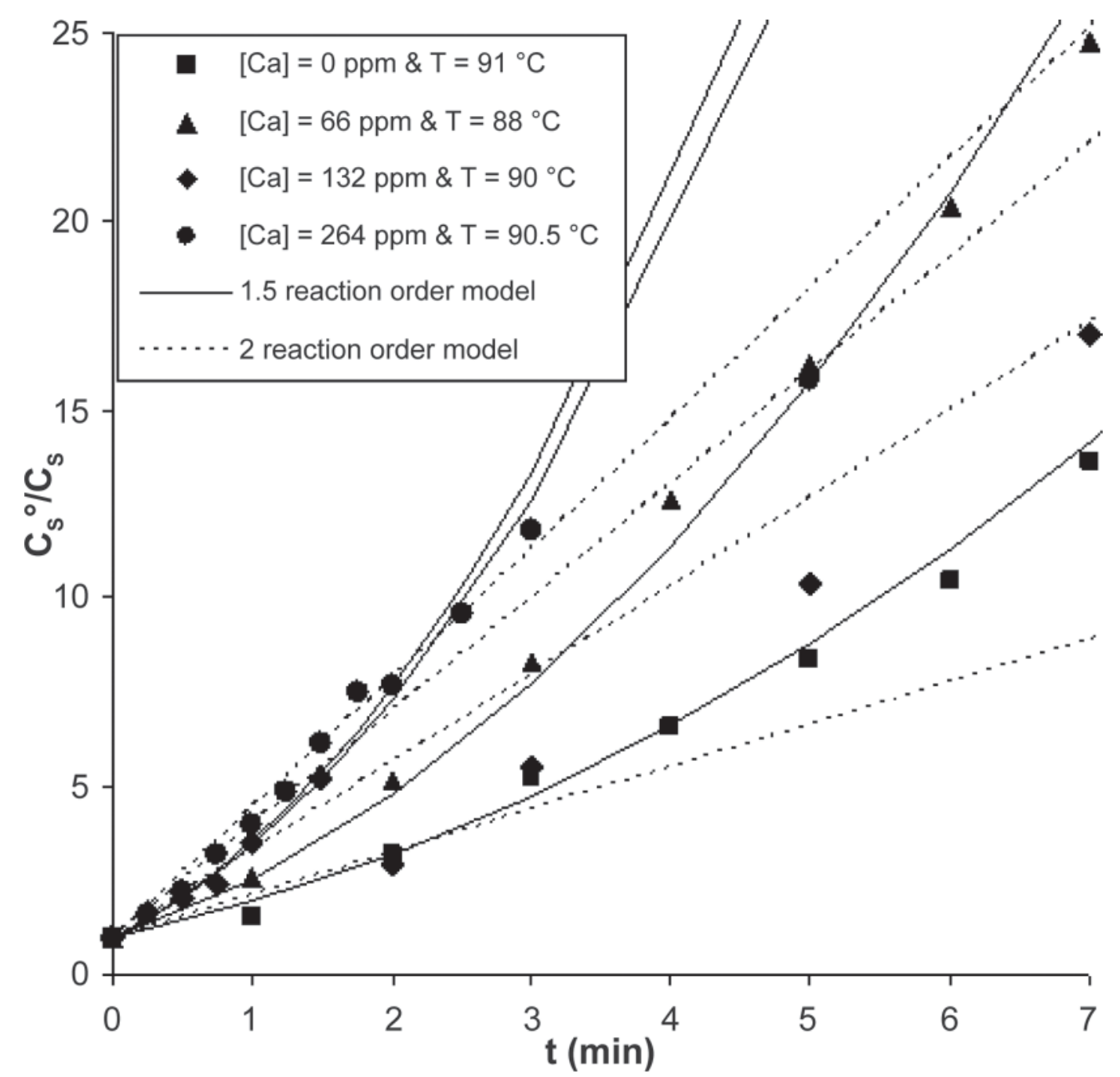

Figure 4. Comparison between the denaturation models based on different reaction orders (1.5 or 2$)$ at approximately $90^{\circ} \mathrm{C}$ and various Ca concentrations. $\mathrm{t}=$ time $(\mathrm{min}) ; \mathrm{C}_{\mathrm{S}}=\beta-\mathrm{LG}$ native concentration at time $\mathrm{t}(\mathrm{g} / \mathrm{L}) ; \mathrm{C}_{\mathrm{S}}{ }^{\circ}=$ initial $\beta$-LG native concentration $(53.3 \mathrm{~g} / \mathrm{L})$.

Galani and Apenten, 1999; Sava et al., 2005; Tolkach and Kulozik, 2007). Sava et al. (2005), working on $\beta$-LG surface thiol groups, found a result $\left(80^{\circ} \mathrm{C}\right)$ similar to that in the present study.

The discrepancy in critical temperature encountered here may be explained by the multiple factors influencing $\beta$-LG denaturation, such as the nature of the heattreated solution, chemical environment, $\beta$-LG concentration, heat temperature profile, hydrodynamics, analytics, and so on. An accurate determination of the Arrhenius critical temperature would require additional trials, but this was not the main goal of the current study.

With regard to the influence of $\mathrm{Ca}$ on $\beta-\mathrm{LG}$ denaturation kinetics, Figure 5 shows that the kinetic rates increased strongly with $\mathrm{Ca}$ concentration. In terms of $\ln k_{n}$, this increase was equal to 0.92 at $70^{\circ} \mathrm{C}, 1.27$ at $80^{\circ} \mathrm{C}$, and 1.54 at $95^{\circ} \mathrm{C}$, when the $\mathrm{Ca}$ concentration was increased from 0 to $264 \mathrm{mg} / \mathrm{kg}$. The kinetic rate increase with $\mathrm{Ca}$ concentration is more important in the aggregation-limited range. This indicates that $\mathrm{Ca}$ acts principally on $\beta-\mathrm{LG}$ aggregation. Indeed, in these conditions, the free $\mathrm{Ca}$ ion $\left(\mathrm{Ca}^{2+}\right)$ is expected to reduce the repulsion between the $\beta$-LG species, which are negatively charged at this $\mathrm{pH}$ above the $\beta-\mathrm{LG}$ isoelectric point. It is well known in the literature that $\mathrm{Ca}$ forms bridges that strengthen the aggregates structure (Verheul et al., 1998; Allen and Smith, 2001; Schmitt et al., 2007), but this work clearly shows that $\beta$-LG unfolding kinetics are also influenced by the Ca concentration. That is, both unfolding and aggregation kinetics are enhanced by Ca addition, this effect being more intense in the upper temperature range.

The kinetic rate increase with Ca concentration is not linear: it is more important in the low Ca concentra- 


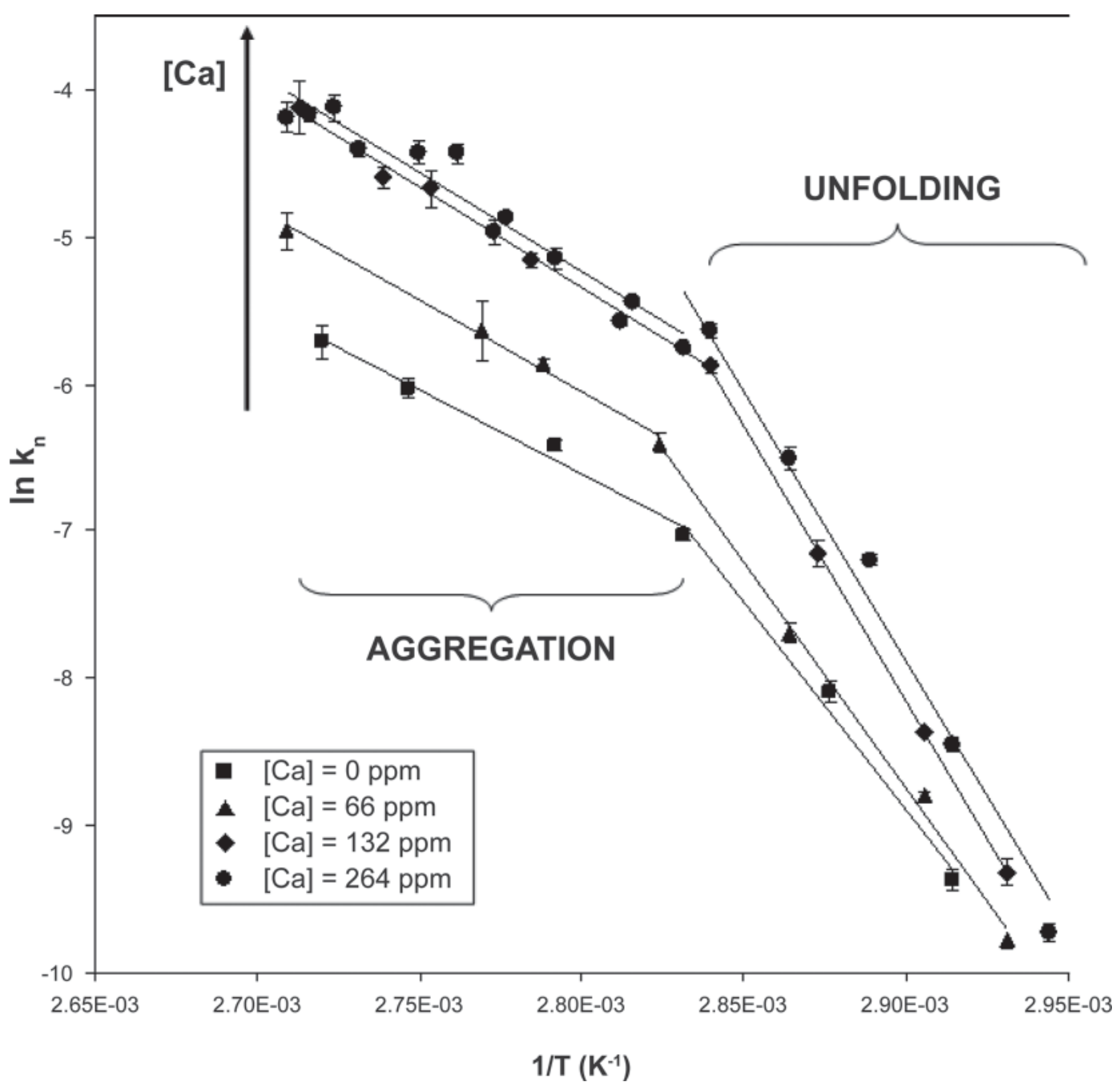

Figure 5. Arrhenius plot for the $\beta$-LG denaturation reaction with 1.5 reaction order at various Ca concentrations. The error bars represent the kinetic rate values and their respective prediction interval. The solid lines correspond to the linear regressions of experimental data. $\mathrm{T}=$ temperature in Kelvin $(\mathrm{K}) ; \mathrm{k}_{\mathrm{n}}=$ denaturation reaction rate $\left(\mathrm{g}^{1-\mathrm{n}} \cdot \mathrm{L}^{\mathrm{n}-1} \cdot \mathrm{s}^{-1}\right)$.

tions and for the aggregation reaction. In Figure 5, the curves corresponding to Ca concentrations of 132 and $264 \mathrm{mg} / \mathrm{kg}$ were very close, with a maximum kinetic rate discrepancy equal to 0.25 logarithmic units. This, and the fact that the kinetic rates increased markedly at low Ca concentrations, may indicate a threshold in the Ca effect on $\beta$-LG denaturation: a 2 -fold increase in Ca concentration over $264 \mathrm{mg} / \mathrm{kg}$ would lead to a very small increase in kinetic rate. This can be explained by the $\beta$-LG and Ca concentrations in solution: 53.3 $\mathrm{g} / \mathrm{L} \beta$-LG equals $2.9 \mathrm{mmol} / \mathrm{L}$, whereas $132 \mathrm{mg} / \mathrm{kg} \mathrm{Ca}$ corresponds to $3.3 \mathrm{mmol} / \mathrm{L}$; in other words, the studied solution at a Ca concentration of $132 \mathrm{mg} / \mathrm{kg}$ is an almost equimolar mixture of $\beta-\mathrm{LG}$ and $\mathrm{Ca}$. The $\mathrm{Ca}$ concentration required to trigger $\beta-\mathrm{LG}$ aggregation is known to increase with the number of $\mathrm{Ca}$ ions bound to $\beta$-LG (Simons et al., 2002). Thus, above a certain concentration, $\mathrm{Ca}$ is expected to have antagonistic effects on $\beta$-LG aggregation: on one hand, $\mathrm{Ca}$ accelerates $\beta-L G$ denaturation and aggregation by charge shielding, bridging, or by inducing conformational changes in $\beta$-LG structure (Simons et al., 2002; O'Kennedy and Mounsey, 2009); on the other hand, $\beta$-LG structure is strengthened by binding $\mathrm{Ca}$, because more $\mathrm{Ca}$ is required to initiate $\beta-\mathrm{LG}$ aggregation (Simons et al., 2002). Consequently, the increase in $\beta$-LG aggregation rate with $\mathrm{Ca}$ concentration should be drastically decreased at a certain $\mathrm{Ca}$ concentration, which was observed in our experimental conditions at $132 \mathrm{mg} / \mathrm{kg}$ Ca.

For each $\mathrm{Ca}$ concentration, linear regressions of experimental data in the 2 temperature ranges (unfolding and aggregation limited) were performed and indicated that denaturation kinetic rates varied with temperature. In the upper temperature range (between 
Table 1. Evaluated denaturation parameters at various Ca concentrations and comparison with literature data

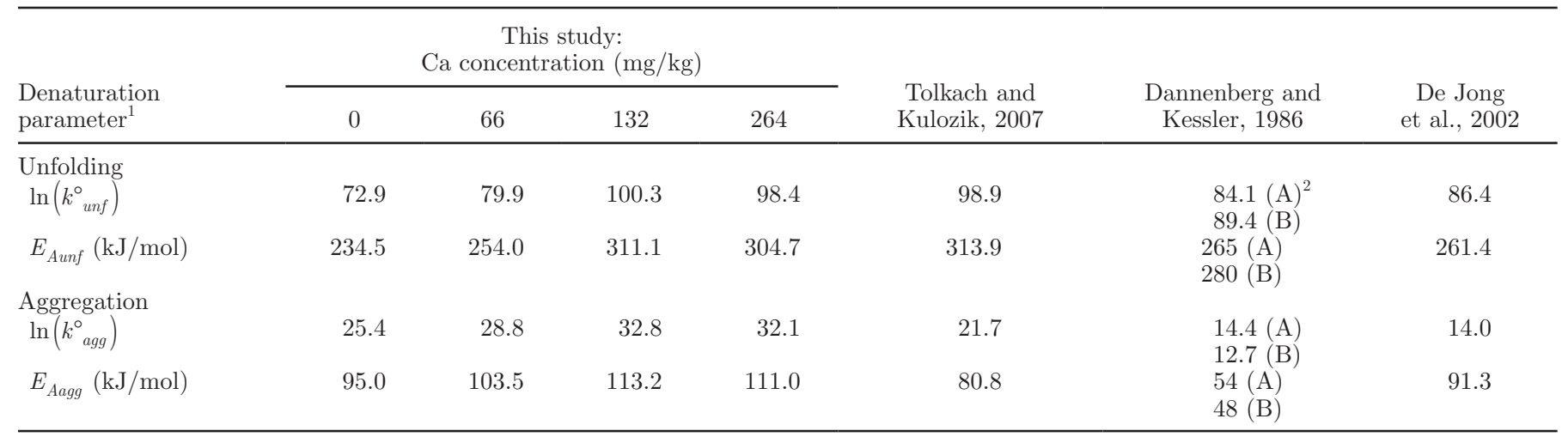

$\overline{{ }^{1} \text { For each denaturation mechanism [unfolding (unf) and aggregation (agg)], ln } \mathrm{k}^{\circ} \text { designates the frequency factor logarithm and } \mathrm{E}_{\mathrm{A}} \text { the activation }}$ energy (see the Arrhenius Equations 7 to 9).

${ }^{2} \mathrm{~A}$ and $\mathrm{B}$ represent the $\beta-\mathrm{LG}$ genetic variants.

80 and $96^{\circ} \mathrm{C}$ ), $\beta$-LG denaturation was limited by the aggregation reaction, so that the aggregation kinetic rate and its evolution with temperature were directly obtained by linear regression of experimental data acquired above $80^{\circ} \mathrm{C}$. The same method was used for data acquired below $80^{\circ} \mathrm{C}$ to determine the kinetic parameters of the unfolding reaction. The obtained frequency factor logarithms $\left(\ln \mathrm{k}^{\circ}\right)$ and activation energies $\left(E_{A}\right)$ are shown in Table 1 and some values found in the literature have been added to allow comparison of our experimental results.

Table 1 shows that our experimental results concerning the unfolding reaction were consistent with the literature values. In fact, in the unfolding-limited temperature range, the calculated frequency factor logarithms and unfolding activation energies at a Ca concentration of $264 \mathrm{mg} / \mathrm{kg}$ were in agreement with the values published by Tolkach and Kulozik (2007), whereas the values from De Jong et al. (2002) and Dannenberg and Kessler (1986) were closer to the results acquired at $66 \mathrm{mg} / \mathrm{kg}$ of $\mathrm{Ca}$. This discrepancy between literature values may result from the different dairy solutions used to study $\beta-L G$ denaturation and particularly from the $\mathrm{Ca}$ concentration. Indeed, it has been noted previously that the kinetic rates increased with Ca concentration. Dannenberg and Kessler (1986) and De Jong et al. (2002) must have used $\beta$-LG solutions with Ca concentrations $<264 \mathrm{mg} / \mathrm{kg}$, which may explain the observed differences with the work of Tolkach and Kulozik (2007). This hypothesis is confirmed by the very low frequency factor logarithms obtained in the present work for $\beta$-LG solutions containing lower Ca concentrations ( 0 and $66 \mathrm{mg} / \mathrm{kg}$ ), which were even inferior to the literature values.

In the aggregation-limited range, we obtained results consistent with those of Tolkach and Kulozik (2007),
De Jong et al. (2002), and Dannenberg and Kessler (1986), although our values were a little greater. This means that $\beta$-LG aggregation was faster under our conditions, most likely because of the relatively high $\beta$-LG concentration $(5.33 \% \mathrm{wt} / \mathrm{wt})$ of the investigated $\beta$-LG concentrate. This was confirmed by the greater discrepancy between our values and the literature results for the aggregation reaction compared with the unfolding reaction: the higher the $\beta-\mathrm{LG}$ concentration, the more frequent are the collisions between reactive $\beta$-LG. Thus, increases in $\beta-\mathrm{LG}$ concentration are expected to affect principally the aggregation behavior.

With regard to the influence of $\mathrm{Ca}$ on $\beta$-LG denaturation kinetics, we can deduce from the values in Table 1 that Ca contributes to increase the kinetic parameters, both in the unfolding and aggregation limited temperature ranges. However, it should be noted that the few measures at each Ca concentration except $264 \mathrm{mg} / \mathrm{kg}$ (about 6 or 7 experiments between 68 and $96^{\circ} \mathrm{C}$ ) can generate imprecision in the evaluation of kinetic parameters. Nevertheless, these results may give a correct insight into the role of $\mathrm{Ca}$ concentration in the $\beta$-LG denaturation mechanism.

On one hand, the great increase in unfolding activation energy between 0 and $264 \mathrm{mg} / \mathrm{kg}$ of $\mathrm{Ca}$ indicates that the unfolding reaction needs more energy to initiate at higher $\mathrm{Ca}$ concentrations, which means that the native $\beta-L G$ is more difficult to unfold in the presence of Ca. Therefore, the Ca ions should have a protective effect against $\beta$-LG unfolding, from a purely thermodynamic point of view. This can be explained by the fact that $\mathrm{Ca}$ alters the native $\beta$-LG tertiary structure and forms intramolecular bonds with some (previously hidden) negatively charged groups, leading to reinforcement of the $\beta$-LG native structure. This hypothesis is consistent with the increase in Ca-binding ability of 
unfolded proteins (Jeyarajah and Allen, 1994). The measured unfolding activation energies have high values $(\sim 300 \mathrm{~kJ} / \mathrm{mol})$; that is, $\beta$-LG unfolding is a strongly endothermic reaction. This indicates that the unfolding reaction corresponds to the break of numerous hydrogen or hydrophobic bonds (each releasing a few kilojoules per mole). The increase in $\beta$-LG unfolding activation energy with Ca concentration is a sign of a greater degree of binding in $\beta$-LG proteins containing $\mathrm{Ca}$, which confirms our previous hypothesis of $\beta-\mathrm{LG}$ structure reinforcement being due to Ca binding.

On the other hand, our data indicate that the unfolding kinetic rate at a given temperature increases with Ca concentration, because of the significant increase of the frequency factor (its logarithm moved from 73 to 100 in the Ca concentration range of this work). From a kinetic point of view, $\beta$-LG unfolding is facilitated by $\mathrm{Ca}$ addition. This can be related to the partial $\beta-\mathrm{LG}$ unfolding induced by $\mathrm{Ca}$, which leads to thiol exposure and enhances $\beta-L G$ denaturation, via the formation of intermolecular disulfide bonds (Jeyarajah and Allen, 1994).

In the aggregation-limited temperature range, activation energy increased slightly from 0 to $264 \mathrm{mg} / \mathrm{kg}$ of $\mathrm{Ca}$, which is surprising given that aggregation is known to be favored in the presence of Ca (Verheul et al., 1998; Allen and Smith, 2001; Schmitt et al., 2007) by means of charge shielding, bridging, or by inducing conformational changes in $\beta$-LG structure (Simons et al., 2002; O'Kennedy and Mounsey, 2009). The observed increase in $\beta$-LG aggregation activation energy may derive from the trigger effect due to Ca-binding: the greater the number of $\mathrm{Ca}$ ions bound to $\beta$-LG, the higher the $\mathrm{Ca}$ concentration required to induce significant $\beta-\mathrm{LG}$ aggregation (Jeyarajah and Allen, 1994). The higher activation energy in the presence of Ca may be related to the additional noncovalent interactions devoted to Ca binding.

As for the unfolding reaction, the aggregation frequency factor increased strongly with Ca concentration (from 25 logarithm units without Ca to 32 logarithm units at $264 \mathrm{mg} / \mathrm{kg}$ of $\mathrm{Ca}$ ), which compensates the higher activation energy required to initiate the aggregation reaction; thus, this allows the aggregation kinetic rate to increase slightly with $\mathrm{Ca}$ content.

Therefore, $\mathrm{Ca}$ has a similar effect on the unfolding and aggregation mechanisms: from the single thermodynamic point of view, Ca seems to protect the native and unfolded $\beta$-LG species by increasing the activation energies required to initiate the unfolding and aggregation reactions, whereas our kinetic results indicate that $\mathrm{Ca}$ enhances the denaturation kinetic rates. These conclusions may appear contradictory at first glance, as we showed that $\mathrm{Ca}$ both favors and limits $\beta$-LG de- naturation, according to the obtained thermodynamic and kinetic results. However, it is not aberrant that both denaturation activation energies and kinetic rates increase with $\mathrm{Ca}$ concentration. In fact, the activation energy represents the required energy to initiate $\beta$-LG denaturation. In our work, $\beta$-LG denaturation was studied between 68 and $96^{\circ} \mathrm{C}$ (i.e., a temperature range in which $\beta$-LG denaturation is observable). Therefore, by applying heating temperatures over $\beta$-LG denaturation temperature, we provided enough energy to the $\beta$-LG solution to initiate $\beta$-LG heat denaturation. This explains why the protective effect of $\mathrm{Ca}$ on $\beta$-LG denaturation was only observable by calculation of thermodynamic parameters (and not by following $\beta$-LG denaturation). One way to illustrate the role of $\mathrm{Ca}$ in $\beta-L G$ denaturation thermodynamics could be to measure the temperature at which $\beta$-LG begins to denature as a function of the Ca content. In our case, Ca would be expected to increase the temperature at which $\beta$-LG begins to denature, as the activation energy increased with Ca content.

With regard to the denaturation kinetic rate, it represents the reaction rate related to $\beta-\mathrm{LG}$ denaturation once this reaction is initiated. Indeed, a reaction must be able to proceed before its kinetic rate can be defined. Whereas the ability to react is described by thermodynamics, how the reaction proceeds once initiated concerns kinetics. Thus, our results, indicating a strong increase in the denaturation kinetic rates with $\mathrm{Ca}$ concentration, show that $\mathrm{Ca}$ favors $\beta$-LG denaturation once this reaction is initiated, which was the case in our operating conditions, as denaturation was detected for all temperatures and Ca concentrations of our experimental set. This explains how Ca can have both protective and destabilizing influences regarding $\beta$-LG denaturation.

The threshold effect of the Ca concentration, which was observed in the Arrhenius plot of Figure 5, can be deduced from the results in Table 1 , as the kinetic parameters for the unfolding and aggregation kinetics reached a plateau from $132 \mathrm{mg} / \mathrm{kg}$ of Ca. Increasing the concentration beyond $132 \mathrm{mg} / \mathrm{kg}$ led to a very small increase in the denaturation kinetic rate.

\section{Denaturation Thermodynamic Parameters}

Thermodynamic parameters for the $\beta$-LG denaturation reaction are shown in Table 2. They were calculated by applying equations [10] to [13] to the experimental data acquired in this study. Thermodynamic data on $\beta$-LG denaturation are rare and the main contribution to these aspects is from Anema and McKenna (1996), which built upon the pioneer work of Dannenberg and Kessler (1986). 
By examining Table 2, good agreement is seen between the results obtained in this work at $66 \mathrm{mg} / \mathrm{kg}$ and that of Anema and McKenna (1996), for which we estimated the Ca concentration to be about $80 \mathrm{mg} / \mathrm{kg}$, especially with the A genetic variant of $\beta$-LG. Indeed, the free energy of activation $\Delta \mathrm{G}$, activation enthalpy $\Delta \mathrm{H}$, and activation entropy $\Delta \mathrm{S}$ were almost identical in the unfolding temperature range and very close in the aggregation limited range, except for $\Delta \mathrm{H}$ over the Arrhenius critical temperature. The differences observed in the aggregation area between our study and data from the literature can be explained by the difference in Arrhenius critical temperature $\left(80^{\circ} \mathrm{C}\right.$ in this study versus $85^{\circ} \mathrm{C}$ in Anema and McKenna, 1996) and by the use of dissimilar $\beta$-LG solutions ( $\beta$-LG powder solution in our study vs. reconstituted whole milk in the latter study) and different $\mathrm{Ca}$ concentrations.

The free energy of activation values were, for all temperatures very close to $100 \mathrm{~kJ} / \mathrm{mol}$, corresponding to what is expected for protein unfolding. Anema and McKenna (1996) discussed that such a $\Delta \mathrm{G}$ range is common for this kind of reaction, with data based on older research in which 18 different proteins were studied.

The evolution of activation entropy with temperature reinforced the idea that the overall denaturation reaction is a 2 step-mechanism (unfolding and aggregation) governed mainly by temperature. Indeed, we can see that the entropy was drastically lower in the aggregation temperature range. In fact, high activation energy and entropy values are indicators of a high degree of $\beta-\mathrm{LG}$ intramolecular binding. This point is also reinforced by the enthalpy decrease between the unfolding and aggregation temperature ranges. Such an enthalpy decrease indicates that the break of intramolecular chemical bonds under heating is shackled over the Arrhenius critical temperature.

In the present work, the determined value for the enthalpy of activation was reduced by a factor of 3 when the temperature was increased above $80^{\circ} \mathrm{C}$ and the entropy of activation was reduced to one-tenth. This implies that $\beta-\mathrm{LG}$ intramolecular bonds are broken mainly in the first denaturation step, which corresponds to $\beta$-LG unfolding. This is related to the conformational change occurring in this lower temperature range: $\beta$-LG unfolds, which involves the breaking of several noncovalent bonds that were essential to stabilization of the native structure. Additionally, the high positive value of activation entropy observed under the Arrhenius critical temperature indicates a significant reduction of $\beta-\mathrm{LG}$ state of order, supporting the thesis of the intramolecular bonds breakage.

Regarding the upper temperature range, the activation enthalpy $\Delta \mathrm{H}$, entropy $\Delta \mathrm{S}$, and energy $E_{A}$ were

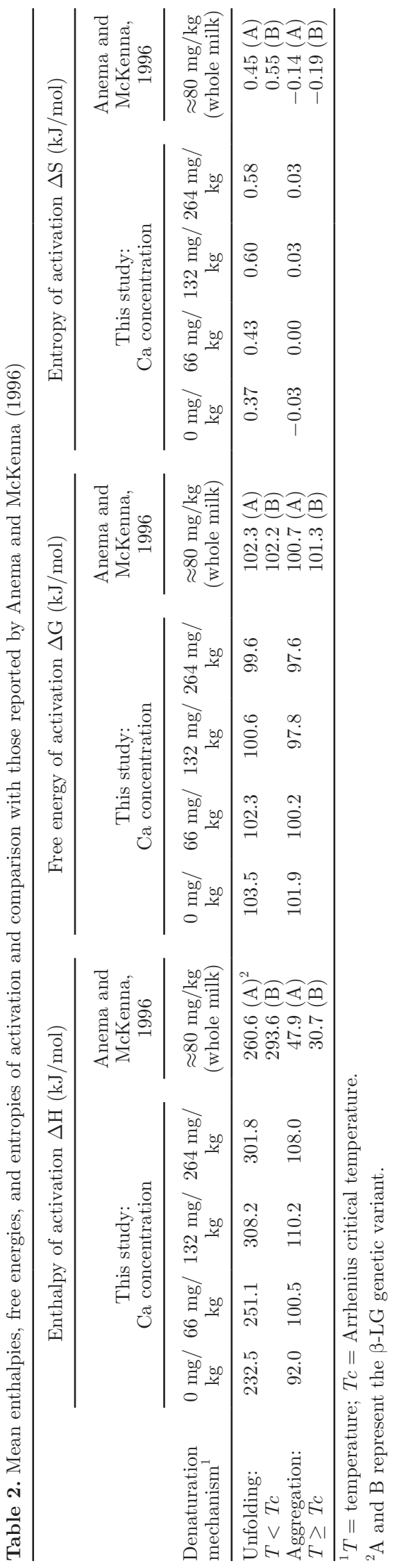


lowered, which denote a strong change in the denaturation mechanism. This temperature range mechanism involves almost no breakage or formation of intramolecular bonds, because of the almost zero activation entropy. Consequently, the $\beta$-LG state of order remained similar, which is consistent with the aggregation mechanism expected to occur above the Arrhenius critical temperature.

With regard to the influence of $\mathrm{Ca}$ on $\beta$-LG denaturation thermodynamic parameters, $\Delta \mathrm{G}$ was almost unaffected by a Ca concentration increase, whereas the $\Delta \mathrm{H}$ and $\Delta \mathrm{S}$ values were significantly increased. Therefore, on one hand, the observed reaction type remained the same at various $\mathrm{Ca}$ concentrations: it consisted of $\beta-\mathrm{LG}$ denaturation, as indicated by the almost constant $\Delta \mathrm{G}$ value. On the other hand, the $\Delta \mathrm{H}$ and $\Delta \mathrm{S}$ increases are attributable to the reinforcement of the native $\beta-L G$ intramolecular bond network because of the increased presence of Ca. The $\beta$-LG native structure is also expected to be strengthened by the fact that $\mathrm{Ca}$ binds 2 parts of the $\beta$-LG polypeptide chain, by bridging 2 negatively charged groups such as carboxylates (Simons et al., 2002). Thus, the presence of Ca significantly stabilizes the tertiary structure of $\beta-\mathrm{LG}$, as attested in the unfolding limited temperature range by the clear $\Delta \mathrm{H}$ increase from 233 to $302 \mathrm{~kJ} / \mathrm{mol}$ between 0 and $264 \mathrm{mg} / \mathrm{kg} \mathrm{Ca}$. The same trend was shown in the $\Delta \mathrm{S}$ values (from 0.37 to $0.58 \mathrm{~kJ} / \mathrm{mol}$ ), which confirms that the native $\beta$-LG state of order increases with $\mathrm{Ca}$ concentration, as expected in case of increased noncovalent bonds in the $\beta$-LG structure.

Similar observations were made in the aggregation limited temperature range, but the Ca effect was less intense: $\Delta \mathrm{H}$ increased from 92 to $108 \mathrm{~kJ} / \mathrm{mol}$ in the studied $\mathrm{Ca}$ concentration range, while $\Delta \mathrm{S}$ remained quasi constant, which indicates that $\mathrm{Ca}$ had little protective effect on the $\beta$-LG molten globule state. Calcium also strengthens the network of noncovalent binding interactions of unfolded $\beta$-LG, even though its role is more important in stabilization of the $\beta$-LG native structure. This result may derive both from the trigger effect of $\mathrm{Ca}$ on $\beta$-LG aggregation (Simons et al., 2002) and from the partial $\beta$-LG unfolding induced by Ca ions, which favors $\beta$-LG denaturation and aggregation (Jeyarajah and Allen, 1994).

The $\beta$-LG concentrate used in this study has been kinetically qualified and the calculation of thermodynamic parameters has shed light on the denaturation mechanisms (unfolding and aggregation), their respective predominance ranges, and their modification in the presence of various Ca concentrations. In the last part of this paper, we will illustrate the Ca influence at different temperatures by examining the temporal evolution of $\beta$-LG denaturation at different fixed $\mathrm{Ca}$ concentrations and temperatures.

\section{Influence of Ca on the Temporal Evolution of Denaturation at Different Temperatures}

The last part of the experimental section will discuss the effect of $\mathrm{Ca}$ on $\beta$-LG denaturation at various temperatures. We have chosen to illustrate the role of $\mathrm{Ca}$ in the unfolding and aggregation limited temperature ranges (at 70 and $90^{\circ} \mathrm{C}$, respectively) and at the $\mathrm{Ar}$ rhenius critical temperature of our system $\left(80^{\circ} \mathrm{C}\right)$. The computed results are given in Figure 6, which shows the evolution of denaturation at $0,66,132$, and 264 $\mathrm{mg} / \mathrm{kg} \mathrm{Ca}$ and at 70,80 , and $90^{\circ} \mathrm{C}$. The denaturation level represents the proportion of $\beta-L G$ proteins that have been converted into aggregates; that is, $1-\frac{C_{S}}{C_{S}{ }^{\circ}}$.

As expected from the form of the Arrhenius equation (equation [7]) and in the conclusions built on the results in Figure 5, the denaturation level increased faster (i.e., the denaturation rate was higher) when the temperature increased. Near full denaturation (a denaturation level >90\%), in the absence of $\mathrm{Ca}$, was reached in about $6 \mathrm{~min}$ at $90^{\circ} \mathrm{C}$ and around $30 \mathrm{~min}$ at $80^{\circ} \mathrm{C}$, whereas at $70^{\circ} \mathrm{C}$, a heat treatment of 60 min was insufficient to denature almost all of the native $\beta-\mathrm{LG}$ (data not shown).

The denaturation level curves had a characteristic shape with a high denaturation rate from the beginning of the heat treatment (see equation [2] with high $C_{s}$ values) until the $\beta-\mathrm{LG}$ native concentration was reduced by half. Then, the denaturation rate decreased even more and converged on very low values when the denaturation level was approaching 80 to $90 \%$.

The computed evolutions of denaturation level related to the whole $\mathrm{Ca}$ concentration range were distributed in well-separated curves, except at $90^{\circ} \mathrm{C}$ and $0 \mathrm{mg} / \mathrm{kg} \mathrm{Ca}$, whose results were very similar to those at $80^{\circ} \mathrm{C}$ and the 2 highest $\mathrm{Ca}$ concentrations. This confirms the strong increases in denaturation rate and level with temperature. In each set of curves, the denaturation level increased with the $\mathrm{Ca}$ concentration, which indicates that the denaturation mechanisms are catalyzed by the presence of $\mathrm{Ca}$. At $70^{\circ} \mathrm{C}$, the discrepancy between the curves was significant and regular, whereas at higher temperatures $\left(80\right.$ and $\left.90^{\circ} \mathrm{C}\right)$, the modification of the $\mathrm{Ca}$ concentration seems at first glance to have a lesser effect on the denaturation level. At the latter temperatures, the threshold effect in the Ca influence on $\beta$-LG denaturation, already discussed in the denaturation kinetic parameters determination, is very apparent in Figure 6, as the denaturation levels at 132 and $264 \mathrm{mg} / \mathrm{kg}$ of $\mathrm{Ca}$ 


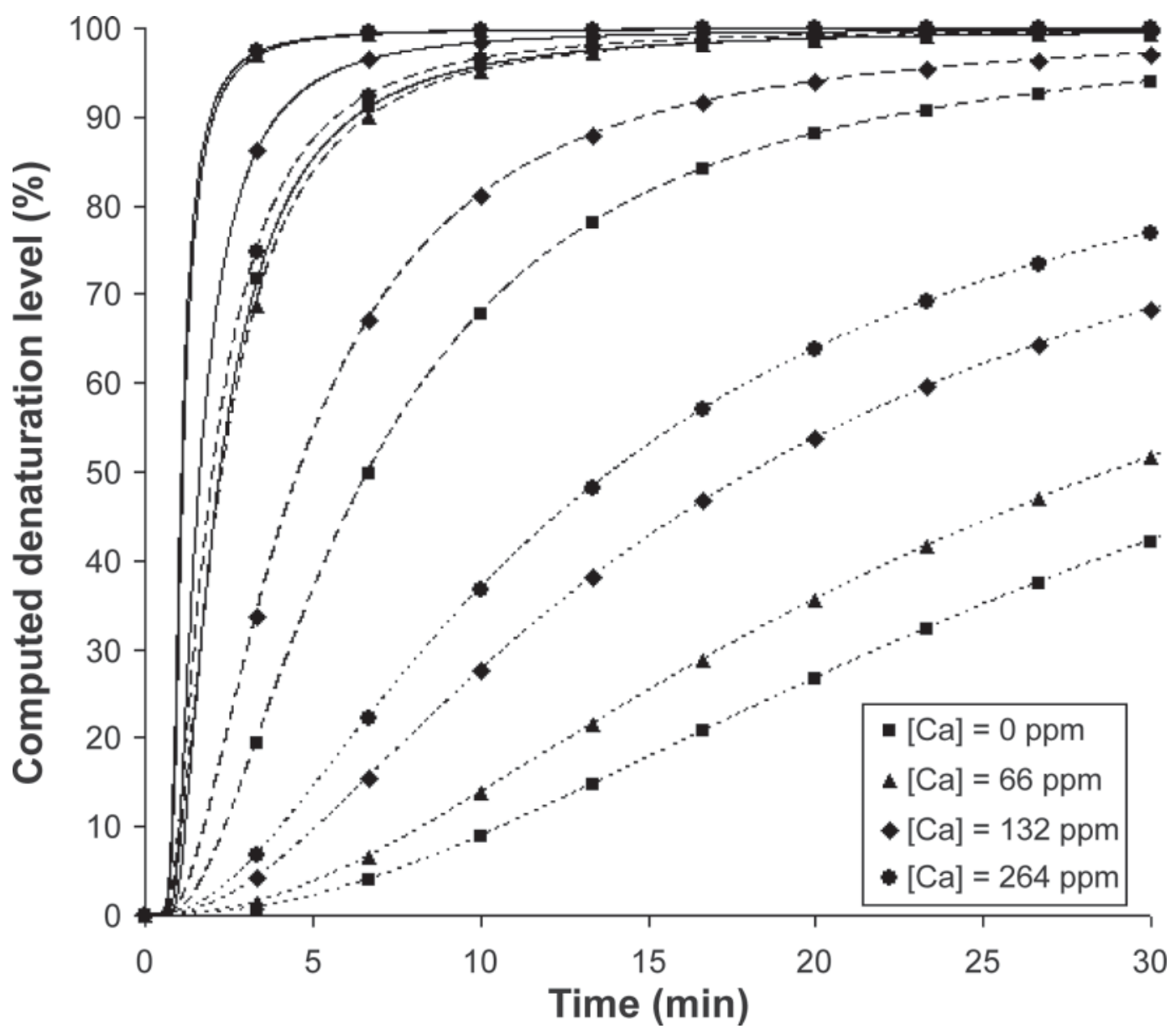

Figure 6. Evolution of $\beta-\mathrm{LG}$ denaturation level at various $\mathrm{Ca}$ concentrations and temperatures $\left(\right.$ dotted line $=70^{\circ} \mathrm{C}$, dashed line $=80^{\circ} \mathrm{C}$, and solid line $=90^{\circ} \mathrm{C}$ ).

were very close or identical. In view of these elements, it could be suggested that Ca has a greater influence on $\beta$-LG denaturation at low temperatures. Therefore, $\mathrm{Ca}$ would be expected to interfere with the unfolding mechanism, which would be accelerated from small Ca additions. In actuality, although $\mathrm{Ca}$ had a more apparent effect on $\beta$-LG denaturation at low temperatures (Figure 6; the denaturation level increased progressively with the Ca concentration), Ca influenced the aggregation mechanism more, as can be deduced from the kinetic rate measurements. Indeed, the maximal denaturation level difference between the 2 extreme Ca concentrations ( 0 and $264 \mathrm{mg} / \mathrm{kg}$ ) was greater at higher temperatures. At $90^{\circ} \mathrm{C}$, the denaturation level at about 0.8 to 1 min moved from 10 to $80 \%$ between 0 and 264 $\mathrm{mg} / \mathrm{kg}$; at $80^{\circ} \mathrm{C}$ and $5 \mathrm{~min}$, from 40 to $90 \%$; and at $70^{\circ} \mathrm{C}$, only from 20 to $60 \%$. Thus, we concluded that $\mathrm{Ca}$ alters aggregation more than denaturation, especially at short heat treatment times, as in industrial pasteurization facilities, for instance. Therefore, these findings explain why Ca initially seemed to be more significant at high time ranges and low temperatures (i.e., in the unfolding limited range), whereas its role in the aggregation temperature range is actually predominant.

\section{CONCLUSIONS}

The calculation of the kinetic parameters allowed us to evaluate the reaction order value that was the best fit to the $\beta-\mathrm{LG}$ denaturation behavior: 1.5.

The critical temperature that splits the Arrhenius plot in 2 linear parts was estimated at $80^{\circ} \mathrm{C}$, each temperature range being related to the predominance of the unfolding or aggregation mechanisms, which constitute the 2 -step reaction path of the $\beta$-LG denaturation. The $\mathrm{Ca}$ effect was more important in the aggregation limited temperature range, indicating that $\mathrm{Ca}$ acts principally on $\beta$-LG aggregation by lowering the Coulombian barrier between 2 negatively charged molten globule or aggregated $\beta-\mathrm{LG}$, by bridge formation, or via an 
ion-specific conformational interaction. Its role in $\beta$-LG unfolding was limited to the reinforcement of the native $\beta$-LG tertiary structure. This was consistent with Ca trigger effect previously described in the literature.

The calculation of the unfolding and aggregation thermodynamic parameters showed good agreement with literature data. The activation enthalpy and entropy obtained in our work were lower in the aggregation range than in the unfolding one. This signifies that the unfolding mechanism involves the break of numerous intramolecular bonds (high $\Delta \mathrm{H}$ ), reducing the $\beta$-LG state of order (high $\Delta \mathrm{S}$ ), contrary to the high temperature mechanism, whose low $\Delta \mathrm{H}$ and $\Delta \mathrm{S}$ are characteristic of an aggregation reaction preserving the $\beta$-LG state of order, in which few (here, only one) covalent bonds are formed.

From a thermodynamic point of view, Ca has a protective influence principally on native $\beta$-LG but also on its molten globule species; however, from a kinetic point of view, Ca catalyzes both unfolding and aggregation reactions, because the associated kinetic rates were strongly increased in the presence of Ca. This discrepancy between kinetics and thermodynamics shows that $\beta$-LG denaturation is a complex process, catalyzed by high Ca concentrations, with a 2-step mechanism highly dependent on the Ca content. The thermodynamic characterization of $\beta$-LG denaturation is not sufficient to predict the behavior of the different $\beta-L G$ species in complex environments, which may explain why the kinetic evaluation is so common in $\beta-\mathrm{LG}$ studies, whereas thermodynamics are rarely discussed, despite the additional information that it provides.

We confirmed by computing the kinetic data that an increase in the Ca concentration promoted $\beta$-LG denaturation mechanisms; namely, unfolding and aggregation. We showed that the results from simulations of $\beta$-LG concentration can be wrongly interpreted, as Ca seemed graphically to enhance $\beta$-LG denaturation particularly at low temperatures. Nevertheless, this interpretation was due to a deceptive impression: $\mathrm{Ca}$ influence is maximal at short treatment times and high temperatures. This last point emphasizes the importance of addition of $\mathrm{Ca}$ when the temperature is high, especially in heat exchangers where $\beta-L G$ solutions are subjected to short-time heat treatments with a final temperature near $100^{\circ} \mathrm{C}$. Monitoring the Ca concentration is a prerequisite for prediction of $\beta-L G$ species concentration within heat exchangers and other chemical facilities.

\section{ACKNOWLEDGMENTS}

This work was carried out within the framework of an ARCIR program (European regional develop- ment fund 09310243 and 03310 241), which joined nonelucidated scientific issues of the Globule project (ANR-08-ALIA-08). The authors thank the Nord-Pasde-Calais region and the Agence Nationale de la Recherche for their financial support and address a special acknowledgement to G. Ronse (INRA UR638 - Processus aux Interfaces et Hygiène des Matériaux, Villeneuve d'Ascq Cedex, France) for his help in chromatographic analysis.

\section{REFERENCES}

Allen, E., and P. Smith. 2001. A review of particle agglomeration. AEA Technology/Research/Public Service Enterprise Group. Vol. 398. AEA Technology Engineering Services Inc., Sterling, VA.

Anema, S. G., and A. B. McKenna. 1996. Reactions kinetics of thermal denaturation of whey proteins in heated reconstituted whole milk. J. Agric. Food Chem. 44:422-428.

Benning, R., H. Petermeier, A. Delgado, J. Hinrichs, U. Kulozik, and T. Becker. 2003. Process design for improved fouling behaviour in dairy heat exchangers using a hybrid modelling approach. Food Bioprod. Process. 81:266-274.

Britten, M., M. L. Green, M. Boulet, and P. Paquin. 1988. Deposit formation on heated surfaces: Effect of interface energetics. J. Dairy Res. 55:551-562.

Changani, S. D., M. T. Belmar-Beiny, and P. J. Fryer. 1997. Engineering and chemical factors associated with fouling and cleaning in milk processing. Exp. Therm. Fluid Sci. 14:392-406.

Dannenberg, F., and H. G. Kessler. 1986. Reaction kinetics of the denaturation of whey proteins. Pages 335-346 in Food Engineering and Process Applications. Vol. 1: Transport Phenomena. M. Le Maguer and P. Jelen, ed. Elsevier Applied Science, Amsterdam, the Netherlands.

De Jong, P., S. Bouman, and H. J. L. J. Van der Linden. 1992. Fouling of heat treatment equipment in relation to the denaturation of $\beta$-lactoglobulin. J. Soc. Dairy Technol. 45:3-8.

De Jong, P., M. C. te Giffel, H. Straatsma, and M. M. M. Vissers. 2002. Reduction of fouling and contamination by predictive kinetic models. Int. Dairy J. 12:285-292.

De Wit, J. N. 1990. Thermal stability and functionality of whey proteins. J. Dairy Sci. 73:3602-3612.

De Wit, J. N. 2009. Thermal behaviour of bovine beta-lactoglobulin at temperatures up to $150^{\circ} \mathrm{C}$ : A review. Trends Food Sci. Technol. $20: 27-34$.

Delplace, F., J. C. Leuliet, and D. Levieux. 1997. A reaction engineering approach to the analysis of fouling by whey proteins of a sixchannels-per-pass plate heat exchanger. J. Food Eng. 34:91-108.

Donato, L., C. Schmitt, L. Bovetto, and M. Rouvet. 2009. Mechanism of formation of stable heat-induced $\beta$-lactoglobulin microgels. Int. Dairy J. 19:295-306.

Foster, C. L., M. Britten, and M. Green. 1989. A model heat-exchange apparatus for the investigation of fouling of stainless steel surfaces by milk. I. Deposit formation at $100^{\circ}$ C. J. Dairy Res. 56:201-209.

Fryer, P. J., G. K. Christian, and W. Liu. 2006. How hygiene happens: Physics and chemistry of cleaning. Int. J. Dairy Technol. 59:76-84.

Galani, D., and R. K. O. Apenten. 1999. Heat-induced denaturation and aggregation of $\beta$-lactoglobulin: Kinetics of formation of hydrophobic and disulphide-linked aggregates. Int. J. Food Sci. Technol. 34:467-476.

Georgiadis, M. C., G. E. Rotstein, and S. Macchietto. 1998. Modelling and simulation of complex plate heat exchanger arrangements under milk fouling. Comput. Chem. Eng. 22(Suppl.):331-338.

Gotham, S. M., P. J. Fryer, and A. M. Pritchard. 1992. $\beta$-lactoglobulin denaturation and aggregation reactions and fouling deposit formation: A DSC study. Int. J. Food Sci. Technol. 27:313-327.

Grijspeerdt, K., L. Mortier, J. De Block, and R. Van Renterghem. 2004. Applications of modelling to optimise ultra high tempera- 
ture milk heat exchangers with respect to fouling. Food Contr. 15:117-130.

Havea, P., H. Singh, and L. K. Creamer. 2001. Characterization of heat-induced aggregates of $\beta$-lactoglobulin, $\alpha$-lactalbumin and bovine serum albumin in a whey protein concentrate environment. J. Dairy Res. 68:483-497.

Jeyarajah, S., and J. C. Allen. 1994. Calcium binding and salt-induced structural changes of native and preheated beta-lactoglobulin. J. Agric. Food Chem. 42:80-85.

Jun, S., and V. M. Puri. 2007. Plate heat exchanger: Thermal and fouling analysis. Pages 417-430 in Computational Fluid Dynamics in Food Processing. D.-W. Sun, ed. CRC Press, New York, NY.

Kim, J. C., and D. B. Lund. 1998. Milk protein/stainless steel interaction relevant to the initial stage of fouling in thermal processing. J. Food Process Eng. 21:369-386.

Labouré, H., E. Cases, and P. Cayot. 2004. Heat induced $\beta$-lactoglobulin polymerization: Role of change in medium permittivity. Food Chem. 85:399-406.

Lalande, M., F. René, and J.-P. Tissier. 1989. Fouling and its control in heat exchangers in the dairy industry. Biofouling 1:233-250.

Linmark-Mansson, H., A. Timgren, G. Alden, and M. Paulsson. 2005. Two-dimensional gel electrophoresis of proteins and peptides in bovine milk. Int. Dairy J. 15:111-121.

Mulvihill, D. M., and M. Donovan. 1987. Whey proteins and their thermal denaturation-A review. Irish J. Food Sci. Technol. 11:43-75.

Nielsen, B. T., H. Singh, and J. M. Latham. 1995. Aggregation of bovine $\beta$-lactoglobulin $\mathrm{A}$ and $\mathrm{B}$ on heating at $75^{\circ} \mathrm{C}$. Int. Dairy J. 6:519-527.

O'Kennedy, B. T., and J. S. Mounsey. 2009. The dominating effect of ionic strength on the heat-induced denaturation and aggregation of beta-lactoglobulin in simulated milk ultrafiltrate. Int. Dairy J. 19:123-128.

Oldfield, D. J., H. Singh, and M. W. Taylor. 2005. Kinetics of heat induced whey protein denaturation and aggregation in skim milks with adjusted whey protein concentration. J. Dairy Res. 72:369 378.

Perez, O. E., and A. M. R. Pilosof. 2004. Pulsed electric effects on the molecular structure and gelation of $\beta$-lactoglobulin concentrate and egg white. Food Res. Int. 37:102-110.

Relkin, P. 1996. Thermal unfolding of $\beta$-lactoglobulin, $\alpha$-lactalbumin, and bovine serum albumin: A thermodynamic approach. Crit. Rev. Food Sci. Nutr. 36:565-601.

René, F., and M. Lalande. 1988. Descriptions et mesures des phénomènes d'encrassement des échangeurs de chaleur. Cas du traitement thermique du lait. Entropie 139:13-23.
Roefs, S. P. F. M., and K. G. De Kruif. 1994. A model for the denaturation and aggregation of $\beta$-lactoglobulin. Eur. J. Biochem. $226: 883-889$.

Rosamininho, R., O. Santos, T. Nylander, M. Paulsson, M. Beuf, T. Bezenech, S. Yiantsios, N. Andritsos, A. Karabelas, G. Rizzo, H. Müller-Steinhagen, and L. F. Melo. 2007. Modified stainless steel surfaces targeted to reduce fouling - Evaluation of fouling by milk components. J. Food Eng. 80:1176-1187.

Santos, O., T. Nylander, M. Paulsson, and A. C. Tragardh. 2006a Whey protein adsorption onto steel-surfaces - Effect of temperature, flow rate, residence time and aggregation. J. Food Eng. 74:468-483.

Santos, O., T. Nylander, K. Schillén, M. Paulsson, and A. C. Tragardh. 2006b. Effect of surface and bulk solution properties on the adsorption of whey protein onto steel surfaces at high temperature. J. Food Eng. 73:174-189.

Sava, N., I. Van der Plancken, W. Claeys, and M. Hendrickx. 2005. The kinetics of heat-induced structural changes of $\beta$-lactoglobulin. J. Dairy Sci. 88:1646-1653.

Schmitt, C. C. Bovay, M. Rouvet, S. Shojaei-Rami, and E. Kolodziejczyk. 2007. Whey protein soluble aggregates from heating with $\mathrm{NaCl}$ : Physicochemical, interfacial and foaming properties. Langmuir 23:4155-4166.

Schraml, J. E., and H. G. Kessler. 1996. Effects of concentration on fouling of whey. Milchwissenschaft 51:151-154.

Simmons, M. J. H., P. Jayaraman, and P. J. Fryer. 2007. The effect of temperature and shear rate upon the aggregation of whey protein and its implication for milk fouling. J. Food Eng. 79:517-528.

Simons, J.-W. F. A.. H. A. Kosters, R. W. Visschers, and H. H. J. de Jongh. 2002. Role of calcium as trigger in thermal beta-lactoglobulin aggregation. Arch. Biochem. Biophys. 406:143-152.

Tolkach, A., and U. Kulozik. 2007. Reaction kinetic pathway of reversible and irreversible thermal denaturation of $\beta$-lactoglobulin. Dairy Sci. Technol. 87:301-315.

Verheul, M., S. P. F. M. Roefs, and K. G. De Kruif. 1998. Kinetics of heat-induced aggregation of beta-lactoglobulin. J. Agric. Food Chem. 46:896-903.

Xiong, Y. L. 1992. Influence of $\mathrm{pH}$ and ionic environment on thermal aggregation of whey proteins. J. Agric. Food Chem. 40:380-384.

Zumaeta, N., E. P. Byrne, and J. J. Fitzpatrick. 2007. Predicting precipitate breakage during turbulent flow through different flow geometries. Colloids Surf. A Physicochem. Eng. Asp. 292:251-263. 